\title{
IMPACT OF URBAN FORMS ON 3D BUILT-UP INTENSITY EXPANSION RATE FROM AERIAL STEREO-IMAGERY
}

\author{
P.W. Mwangi ${ }^{1}$, F.N. Karanja ${ }^{2}$, P.K. Kamau ${ }^{1}$, S.C. Letema ${ }^{3}$ \\ ${ }^{1}$ Dept. of Spatial Planning \& Urban Management, Kenyatta University, Nairobi, Kenya- (mwangi.patricia, kamau.peter)@ku.ac.ke \\ ${ }^{2}$ Dept. of Geospatial Engineering, University of Nairobi, Kenya- faithkaranja@uonbi.ac.ke \\ ${ }^{3}$ Dept. of Environmental Planning \& Management, Kenyatta University, Nairobi, Kenya- letema.sammy@ku.ac.ke
}

Commission IV, WG IV/10

KEY WORDS: Ground Coverage Ratio, Built-up Volume Density, 3D Built-up Intensity, Height, Stereo Imagery, Urban Form

\begin{abstract}
:
Urban areas have been cited to be contributors to changing climatic conditions. Conversion of vegetated areas to impervious surfaces causes an alteration of surface temperatures, where impervious surfaces absorb and store incoming radiation during the day, releasing it slowly at night. This causes the urban heat island effect where temperatures in urban areas are higher than rural areas during night. Extreme weather conditions experienced in urban areas include heat waves, intense rainfall resulting to flash floods, destruction of infrastructure facilities. The research involved the use of time-series of stereo-aerial images acquired in 1978, 2000 and 2017. Building footprints were digitized and using digital elevation models, building heights were derived and volumes calculated. Road volumes were calculated using minimum standards of road construction and the total built-up volume was determined. The ground coverage ratio (GCR) and built-up volume densities (BVD) of the built-up areas was calculated from area and volumes from road and building values. Results indicate the mean GCR and BVD in Upper Hill is within the low density range. Mean building height from 1978 to 2017 are in the low-rise range with significant rise in building height and volumes between 1998 and 2017. The 3D built-up intensity expansion rate ranged between $-4.28 \%$ to $56.80 \%$ per annum with a mean of $19.6 \%$ per annum. Roads and pavements also have a significant influence on the built-up density and should therefore be considered in planning policies.
\end{abstract}

\section{INTRODUCTION}

Space-borne earth observation (EO) is very important in planning for urban areas as it provides up-to-date spatial information. Builtup areas (buildings) and non-built-up areas (open spaces) make up the urban space (Hamaina et al., 2012). Natural features such as trees, vegetation and some man-made objects such as buildings within an urban area comprise a digital image of the earth's surface and is referred to as a 3D city model (Singh, 2013). Various terminologies have been used to describe a 3D city models including a virtual city, digital city, cyber city or cybertown (Singh, 2013). Urban systems are better understood through the use of accurate 3D models, resulting to sustainable urban development (Billen et al., 2014).

The spatial arrangement of the built environment is associated to its function. Land use changes triggered by urban growth and urban fringe expansion leads to loss of biodiversity, natural habitats, watershed degradation and landscape fragmentation (Van de Voorde et al., 2011). Monitoring the spatial impact of urban planning strategies needs functional and morphological land-use maps that indicates continuing urban growth processes (Van de Voorde et al., 2011). Therefore, cities need to be investigated in a holistic way in view of sustainable development of cities where the interrelations of various environmental and urban issues are taken into account (Billen et al., 2014).

Stereo-imagery are useful data for deriving 3D datasets for builtup areas. $3 \mathrm{D}$ visualization in built-up areas is vital in understanding building density (Peng et al., 2016). Generating 3D information also enables stakeholders determine vulnerability of constructed buildings in any geographic area (Eckert, 2008). However, in deriving built-up density the Modifiable Area Unit Problem (MAUP) is unavoidable since density is dependent on area (Popovich et al., 2018).

The rate of urban development needs to be determined as compact cities are considered as sustainable solutions for pressures of urbanization (Argent et al., 2012). Changes in the third dimension should be of great interest to urban designers and climate change policy managers in determining how these developments influence the microclimate and land surface temperature changes.

\section{METHODOLOGY}

\subsection{Study Area}

The area of study is Upper Hill, Nairobi Kenya and covers an area of 4.2 square kilometers. Known as the capital's financial hub, diverse organizations can be found in Upper Hill including commercial centers, hospitals, government institutions, embassies and multi-national companies (UHDA, 2017). Upper Hill has transformed to office block, commercial and high-rise flats from residential use due to policies that have re-zoned the area as well as adjacent areas. Demand of office space from organizations choosing to locate businesses away from the central business district informed the changes in zoning regulations (Kiai et al., 
2008). The urban landscape has changed due to an increase in development where urban greenery has been replaced with concrete (Karanja \& Matara, 2013) subsequently leading to increased land surface temperatures (Mwangi et al., 2018). There currently is no metric system developed to define built-up volume densities and classify them to determine development trends and make necessary decisions in relation to climate change issues. Challenges are faced in urban areas there're lack of indicators on three dimensional development in formulating policies on pollution and thermal comfort in cities.

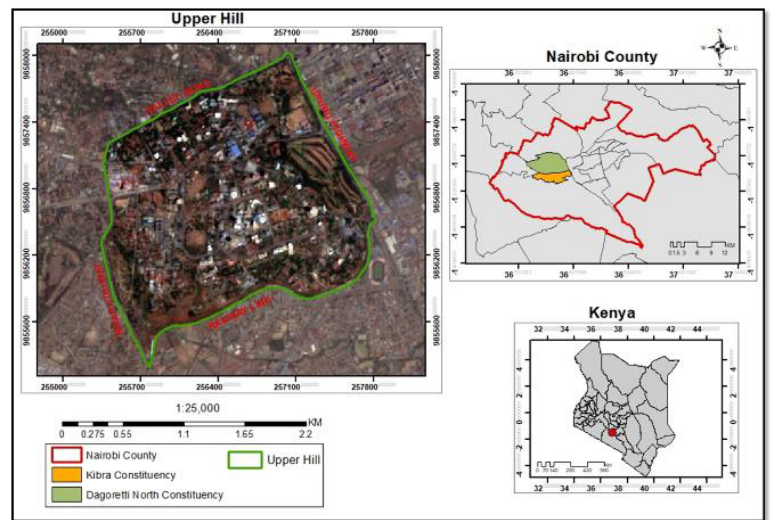

Figure 1: Location of Upper Hill in Nairobi (C) Sentinel Image Copyright 2017

\subsection{Stereo-Orientation}

Stereo-aerial imagery acquired in the years 1978, 1998 and 2017 were used to determine the built-up volume density changes. Summary of processing stereo-imagery is given in figure 2 .

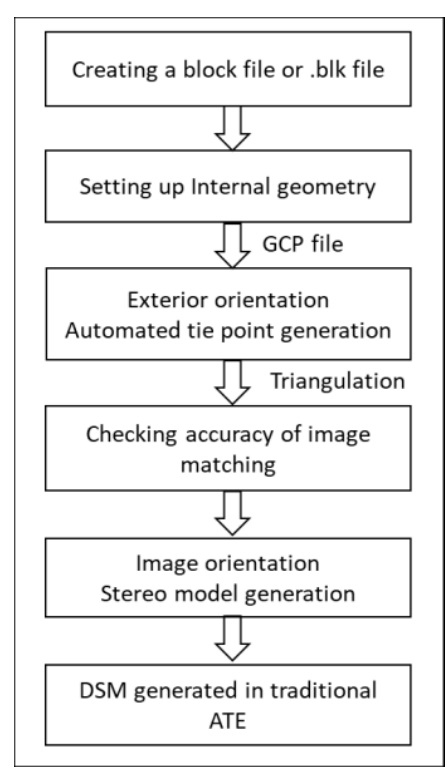

Figure 2: Flow chart of stereo-orientation process (Adopted from: Saha, 2014)

Five stereo-imagery in 1978 at 1:25000 and 1:50000 were scanned, while the 2017 digital stereo- imagery comprised of forty photos at $10 \mathrm{~cm}$ accuracy. 1998 data comprised of digitized datasets from aerial stereo-imagery acquired at a scale of 1:25000. GCP points identified on the ground comprised of road junctions, culverts and easily identifiable features. Observations at each point were done for a period of $10-15$ minutes with a base established at a Survey of Kenya control point at Nyayo Stadium. Differential correction was done using observations from a continuously observing reference station (CORS) located at Regional Center of Mapping \& Regional Development (RCMRD) and reduced to 10 second phase. Summary of the model and block properties set-up are indicated in table 1 .

\begin{tabular}{|l|l|l|}
\hline \multirow{2}{*}{ Model setup } & Frame Camera & 1978 stereo-image \\
\cline { 2 - 3 } & Digital Camera & 2017 stereo-image \\
\hline \multirow{3}{*}{$\begin{array}{l}\text { Block property } \\
\text { setup }\end{array}$} & Projection & UTM Zone 37 South \\
\cline { 2 - 3 } & Datum & Arc 1960 \\
\cline { 2 - 3 } & Spheroid & Clarke 1880 RGS \\
\cline { 2 - 3 } & Rotation System & Omega, Phi, Kappa \\
\hline
\end{tabular}

Table 1: Summary of model and block properties set up

Coordinates, $\mathrm{X}, \mathrm{Y}, \mathrm{Z}$ of common points identified in the 2017 and 1978 image were used as GCP's for orienting the 1978 stereoimagery.

\subsection{Generation of BVD, GCR and FAR}

In the 1998 datasets, a 2 meter DEM was generated from contour lines which were at 2 meter intervals (Figure 3 ).

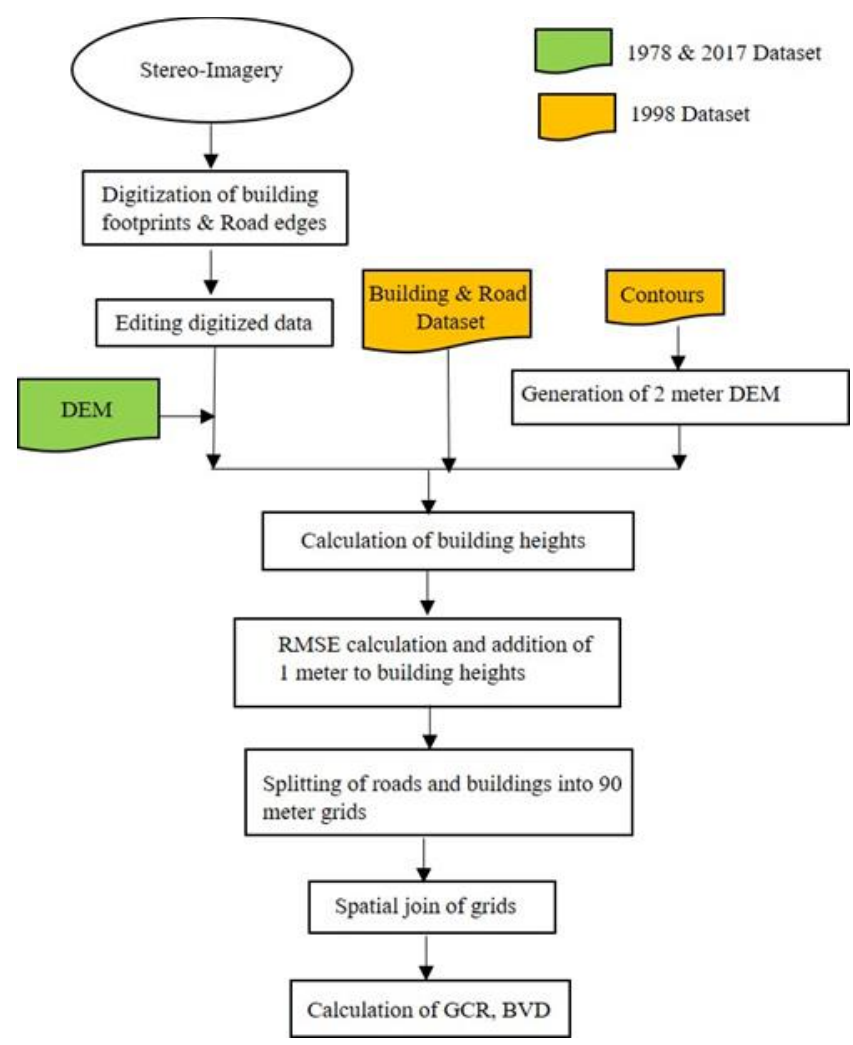

Figure 3: Flowchart of building height, GCR \& BVD generation

For the 2017 dataset, a 5 meter DEM was initially generated by creating a TIN using the control and tie-points generated during the 
orientation process. The DEM was then resampled to 2 meters due to the minimum size of the building footprints. DEM accuracy indicates how precisely the ground truth is represented by the generated DEM (Guo-an et al., 2001). An accuracy assessment of 1978, 1998 and 2017 generated DEMs was carried out with the control points collected during field work as the reference. An RMSE of 1.453, 0.91 and 0.685 meters was obtained for 1978, 1998 and 2017 respectively using equation (1).

$$
R M S E=\sqrt{\frac{\sum_{i=1}^{n}\left(P_{i}-Q_{i}\right)^{2}}{n}}
$$

where: $\quad P_{i}$ is the DEM cell value at $i$

$Q_{i}$ is the corresponding sample point elevation at $i$ $n$ is the number of sample points

The RMSE values were less than the DEM resolution hence the DEMs could be used for further analysis. An orthophoto was generated from 2017 image and used for verification.

Validation of extracted building heights for 1978, 1998 and 2017 was done using actual building height values from Emporis, 2018. Nine buildings were used to validate the 1998 datasets and thirteen buildings to validate the 2017 datasets by calculating the RMSE values. Building heights were calculated using area based point averaging method where DEM pixel values were subtracted from elevation values of digitized buildings. LOD1 was used to reconstruct each building thereby assigning one height value for each building. RMSE value of 1998 and 2017 buildings was 1.12 meters and 0.007292 meters respectively. Therefore 1 meter was added to all buildings for all years. Individual buildings were classified as low, middle or high-rise according to the Kenyan building codes (RoK, 2009) as shown in table 2 .

\begin{tabular}{|l|l|l|}
\hline Name & Height & Floors \\
\hline Low-rise & $\leq 10$ meters & 3 \\
\hline Middle-rise & $10>\mathrm{h} \leq 30$ meters & 3 to 10 \\
\hline High-rise & $>30$ meters & $>10$ \\
\hline
\end{tabular}

Table 2: Building height classification in Kenya

The mean height of buildings in each grid was determined using equation 2 .

$$
H_{w, k}=\frac{\sum_{j=1}^{m} A_{j} H_{j}}{\sum_{j=1}^{m} A}
$$

where: $A_{j}$ area of building $j$

$H_{j} \quad$ height of building $j$

$m$ total number of buildings in the grid

$H_{w, k}$ average weighted height of all buildings in each grid

After splitting buildings along the grid lines, the volume of each building was calculated and the total volume in each grid was summed as shown in equation 3 .

$$
V B_{k}=\sum_{j=1}^{m} A_{j} H_{j}
$$

where: $V B_{k}$ is the volume of buildings in a grid $k$

$A_{j}$ is the area of building $j$

$H_{j}$ is the height of building $j$
The main roads in Upper Hill were considered for volume calculation, while those leading into plot boundaries were ignored. The recommended standard minimum road thickness of 0.3 meters was calculated together with the road area to obtain the road volume. The volume of roads in each grid was calculated as shown in equation 4.

$$
V R_{k}=\sum_{r=1}^{Z} A_{r} T_{r}
$$

where: $\quad V R_{k}$ is the total volume of roads in a grid $k$

$A_{r}$ is the area of the road $r$

$T_{r}$ is the thickness of the road $r$

$z$ is the total number of roads in the grid

Building and road volumes in each grid was determined by spatially joining the two datasets. This was applied for all three years 1978, 1998 and 2017. Built-up volume density was calculated for each grid by dividing the built-up volume in each grid cell by the grid cell area and whose units are $\mathrm{m}^{3} / \mathrm{m}^{2}$ (equation 5).

$$
B V D_{k}=\frac{V B_{k}+V R_{k}}{A_{k}}
$$

where: $B V D_{k}$ is the built-up volume density of buildings and roads within a grid $k$

$A_{k} \quad$ is the area of the grid, $k$

Using changes in built-up volume density between 1978 and 2017, the rate of 3D built-up intensity expansion (Longyu et al., 2009) was calculated for each grid cell using equation 6 .

$$
U L I_{k}=\frac{B V_{u, t+l}-B V_{u, t}}{A_{k}} * \frac{1}{T} * 100 \%
$$

where: $U L I_{k}$ is the intensity of urban expansion at grid $k$

$B V_{u, t+l}$ is the built-up volume in time $t+l$

$B V_{u, t}$ is the built-up volume in time $t$

$T \quad$ is time period between the years

Ground coverage ratio (GCR), floor area ratio (FAR) and built-up volume density (BVD) were used to classify density as either low, medium or high. They were derived from the Nairobi ordinance guiding principles (NCC, 2006) as it does not define density within the criteria developed. The relationship between FAR and BVD was determined using equation 7 .

$$
y * F A R=B V D
$$

where: $y$ is the floor height

The density ranges developed for each measurement of density are shown in table 3 .

\begin{tabular}{|l|c|c|c|}
\hline Ratio & $\begin{array}{c}\text { Low density } \\
(\%)\end{array}$ & $\begin{array}{c}\text { Medium density } \\
\text { (\%) }\end{array}$ & $\begin{array}{l}\text { High } \\
\text { density } \\
\text { (\%) }\end{array}$ \\
\hline GCR & $0>G C R \leq 25$ & $25>G C R \leq 60$ & $>60$ \\
\hline FAR & $0>F A R \leq 75$ & $75>F A R \leq 200$ & $>200$ \\
\hline BVD & $0>B V D \leq 225$ & $225>B V D \leq 600$ & $>600$ \\
\hline
\end{tabular}

Table 3: GCR, FAR and BVD classification 


\section{RESULTS}

Mean GCR from 1978 to 2017 is between $11 \%$ and $19 \%$ while mean BVD is between $55 \%$ and $185 \%$, which are within the low density range (Table 4). Significant percentage changes in density occur between 1998 and 2017 which can be attributed to increased building ground coverage, heights and road widening. The rate of changes in built-up volume was mainly attributed to the changes in building heights with high-rise buildings increasing from 1998 to 2017. This can be attributed to changes in land use from residential to commercial due to the demand of office space.

\begin{tabular}{|c|c|c|c|c|c|}
\hline \multirow{2}{*}{ 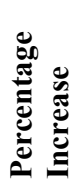 } & $\stackrel{\infty}{\sigma}, \overline{=}$ & $\stackrel{\infty}{n}$ & 导 & fo & F \\
\hline & $\stackrel{\infty}{5}, \stackrel{\infty}{\sigma}$ & $a$ & \& & $n$ & 0 \\
\hline \multirow{2}{*}{ } & $\stackrel{\infty}{\circ}$, & ல̂. & $\stackrel{\infty}{\circ}$ & $\stackrel{\infty}{\sim}$ & बे \\
\hline & $\stackrel{\infty}{\stackrel{\sigma}{\sigma}, ~}$ & $\ddot{0}$ & సֶ & $\frac{1}{0}$ & 0 \\
\hline \multirow{3}{*}{$\stackrel{\dot{\varpi}}{\grave{\nu}}$} & $\overline{\bar{d}}$ & $\frac{9}{0}$ & $\mathscr{\infty}$ & $\begin{array}{l}\infty \\
\infty \\
\sim\end{array}$ & $\stackrel{ \pm}{m}$ \\
\hline & $\stackrel{\text { ڤ̆ }}{2}$ & $\stackrel{I}{\circ}$ & $\stackrel{尺}{\circ}$ & $\begin{array}{l}q \\
\text { in }\end{array}$ & ఝి \\
\hline & $\stackrel{\infty}{5}$ & $\overrightarrow{0}$ & 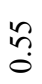 & $\underset{n}{n}$ & חై \\
\hline \multicolumn{2}{|l|}{ 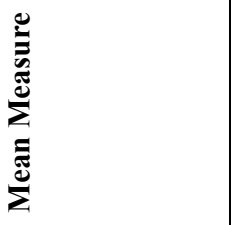 } & 艺 & 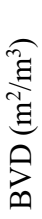 & 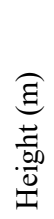 & 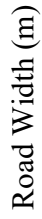 \\
\hline
\end{tabular}

Table 4: Mean GCR, BVD , height and road width from 1978 to 2017

Re-zoning policy changes in Upper Hill were approved in 1995 by Nairobi City County (NCC) and this also contributed to the increase in built-up densities as seen between 1998 and 2017 (Karoki, 2004;UNEP et al., 2009). This resulted to residential houses being demolished for commercial buildings, increasing the plot ratio. Average road widths increased due to road expansions which sought to reduce traffic jam resulting from increased traffic flow within the area. Tarmacking of murram roads and redesigning roads contributed to an increase in road density and consequently the BVD. Roads built before 1978 have been 're-carpeted' therefore also increasing the thickness of the impermeable layer but due to unavailability of this data it was not considered.

Percentage of low-rise buildings in 1978, 1998 and 2017 was $91.6 \%, 90.5 \%$ and $79.8 \%$ respectively while high-rise buildings were at $0.40 \%, 0.50 \%$ and $4.5 \%$ respectively. Low-rise buildings remained the majority in Upper Hill by 2017 even as construction of high-rise buildings increased. In larger cities buildings are made taller due to competition of land with concentration of space in population, economic activity and infrastructure (Schläpfer et al., 2015).
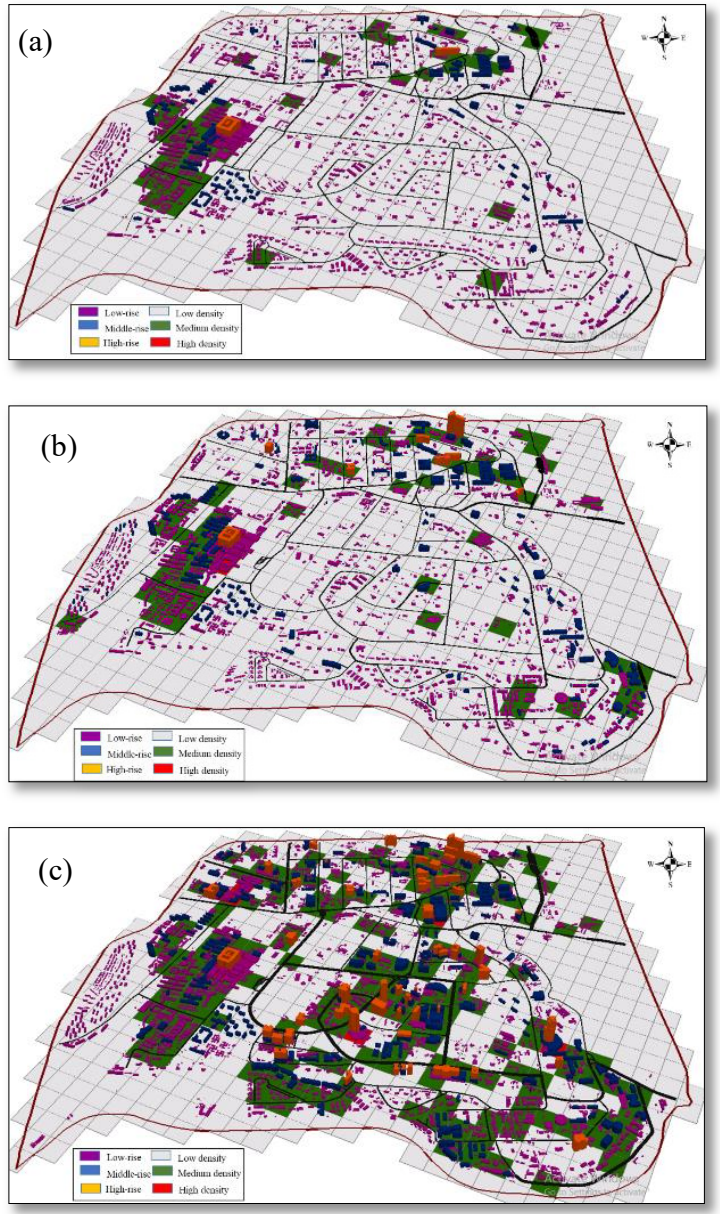

Figure 4: Building height and BVD distribution in 1978 (a), 1998 (b) and 2017 (c)

Changes in built-up density in the area is expressed in terms of GCR and BVD. In 1978 low density GCR and BVD in Upper Hill was at $96.64 \%$ and $94.51 \%$ respectively while high density GCR and BVD was at $0.18 \%$ and $0.88 \%$ respectively (Figure $4 a$ ). High density GCR and BVD is located at Kenyatta National Hospital which is an institutional land use in the west. Open and recreational spaces are concentrated in the eastern and south-western parts of Upper Hill. By 1998, low density GCR and BVD was at $89.7 \%$ and $90.3 \%$ respectively while high density GCR and BVD was at $0.71 \%$ and $1.42 \%$ respectively. High density BVD expanded to the northern part of Upper Hill whose land use is commercial and office (Figure 4b). With rezoning, mixed-use development was encouraged. By 2017, low density GCR and BVD was at $66.6 \%$ and $73.1 \%$ respectively and high density GCR and BVD was at $1.59 \%$ and $8.32 \%$ respectively. Medium GCR density expanded in the north, western and central parts of Upper Hill with high BVD and GCR densities concentrated at institutional and commercial land uses (Figure 4c). However, the western part of Upper Hill comprises of hospital staff quarters and medical facilities which have not changed significantly from their low density form within 
the 39 year time span of study. Recreational spaces, having an area of approximately 72.53 Hectares from 1978 to 2017, had not changed from 1978 but open spaces especially in the central part of the area were developed due to pressures from land use changes. Recreational land uses such as Railways Golf Club, Uhuru Park on the eastern part of the study area, Upper Hill High School field, Nairobi Safari Club, Public Service Club influence the spatial arrangement of built-up areas and also influences the average density in the area. Therefore the quality of spatial elements such as green and open spaces, ventilation, accessibility and day-light access are negatively influenced by high density low-rise built-up forms with high GCR (Sokido, 2016).

The urban space increase, measured by urban expansion is an important index for assessing the process of urbanization (Longyu et al., 2009). The expansion rate enables one to understand the forces that are driving urban growth and the pattern it is following. The 3D built-up intensity expansion growth rate from 1978 to 2019 ranged from $-4.28 \%$ to $56.80 \%$ per annum where negative values indicated demolished buildings and zero values indicated no change (Figure 5).

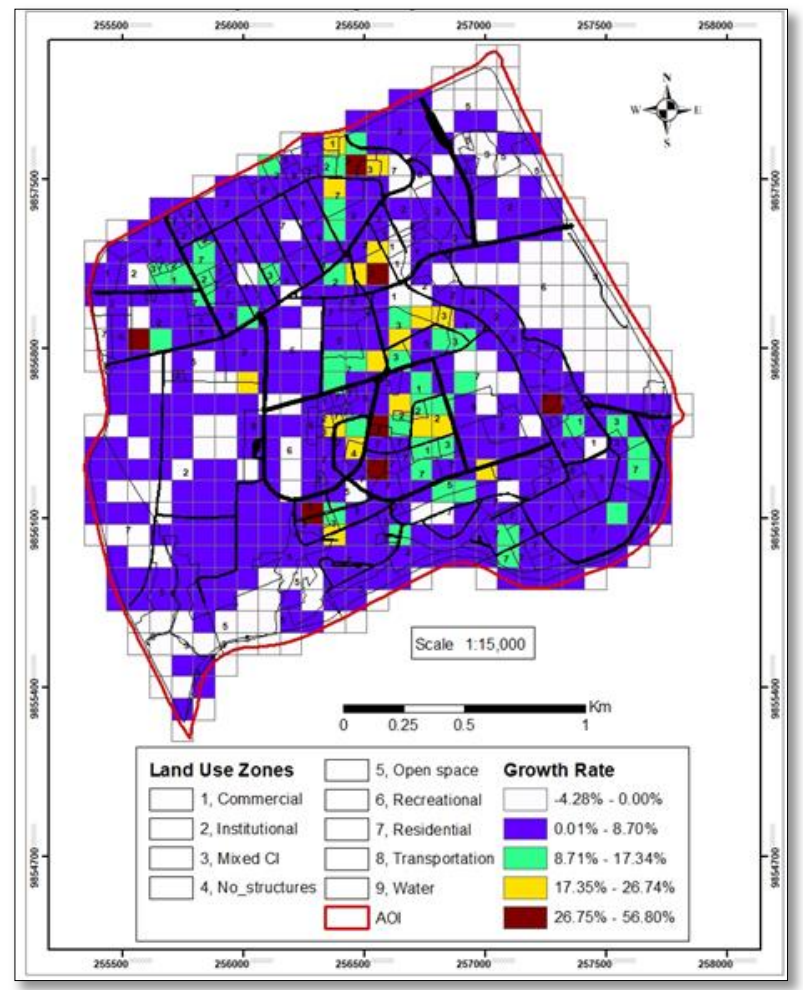

Figure 5: 3D built-up intensity expansion rate from 1978 to 2017

Areas with no changes included recreational spaces and buildings that had not undergone any reconstruction or extension. Institutional land uses and those formerly classified as residential and were converted to commercial/office land uses had the highest rates of between $20.75 \%$ and $56.80 \%$ p.a. These are areas that have high to middle-rise buildings since height is an important factor in BVD. The mean growth rate was at $3.30 \%$ p.a while $20.53 \%$ of Upper Hill had an expansion rate of more than $5 \%$ p.a. Horizontal and vertical expansion mainly occurred between 1998 to 2017 than between 1978 and 1998. This may have driven by economic factors where there was an increase in the construction industry (Wetangula \& Mazurewicz, 2017).

Policies have had an influence on urban expansion in Upper Hill. This can be seen from the type of development which was infilling and redevelopment with the road network influencing the spatial pattern of development. Land use changes are known to have effects on transportation with issues arising from traffic congestion (Karoki, 2004). Urban expansion as seen in Upper Hill is centered on an expanded road network due to increased demand of office space. From a spatial perspective, Upper Hill is growing from a highly vegetated low rise low density area towards a high rise, high density development with the central parts showing higher rates of expansion.

\section{CONCLUSION}

This paper investigated the effect of road density on the built-up density of an urban area and the rate of urban expansion. Consideration of road volumes and area shows a significant effect on the resulting built-up densities indicating that urban density should not only should consider the number of people but also the built-up materials in which people live in. Recreational and open spaces are important as they have a significant effect on the density distribution patterns. Vertical and horizontal expansion changes indicates that vertical urban expansion significantly influences built-up volumes compared to horizontal expansion. This is important as vertical expansion has been advocated for in compact city development in combating climate change. The spatial and temporal development process is better understood from urban expansion which indicates areas where intensity has increased more than others. This can be useful in gaining and understanding on driving forces that influence development within certain periods. Changes in policy on land use have significantly influenced development with development rates increasing after policy changes. Therefore, built-up volume densities of buildings should be considered as an index in analyzing urban spatial development. The research method and process of multi-temporal data can be used in other cities to understand deeper processes of urban expansion.

\section{REFERENCES}

Argent, N. M. J. D., Beringer, J., Tapper, N., \& Coutts, A. (2012). Planning for the Compact City; An Assessment of Melbourne @ 5million. In WSUD 2012: Water sensitive urban design; Building the water sensitive community; 7th international conference on water sensitive urban design (pp. 781-785). Barton, ACT, Australia: Engineers Australia.

Billen, R., Cutting-Decelle, A.-F., Marina, O., de Almeida, J.-P., M., C., Falquet, G., ... Zlatanova, S. (2014). 3D City Models and urban information: Current issues and perspectives. Les Ulis cedex A. doi.org/10.1051/tu0801/201400001

Eckert, S. (2008). 3D-Building Height Extraction from Stereo IKONOS Data. JRC Scientific and Technical Reports. Luxembourg. 
Emporis. (2018). EMPORIS. emporis.com/buildings. (July 2, 2018)

Guo-an, T., Strobl, J., Jian-ya, G., Mu-dan, Z., \& Zhen-jiang, C. (2001). Evaluation on the Accuracy of Digital Elevation Models. Journal of Geographical Sciences, 11(2), 209-216. doi.org/10.1007/BF02888692

Hamaina, R., Leduc, T., \& Moreau, G. (2012). Towards Urban Fabrics Characterization Based on Buildings Footprints. Lecture Notes in Geoinformation and Cartography, 327-346. doi.org/10.1007/978-3-642-29063-3_18

Karanja, F. N., \& Matara, S. (2013). The Transformation from Green to Concrete Cities; A Remote Sensing Perspective. International Archives of the Photogrammetry, Remote Sensing and Spatial Information Sciences - ISPRS Archives, 40(1W1), 163166.

Karoki, E. M. (2004). Examination of Effects of Rezoning on the Transport Demand in Nairobi Hill Area. (E. Karoki, Ed.). University of Nairobi.

Kiai, S. K. (2009). Reversing Horizontal Sprawl: Towards More Compact City Neighbourhoods. Shelter Design \& Development.

Longyu, S., Guofan, S., Shenghui, C., Xuanqi, L., Tao, L., Kai, Y., \& Jingzhu, Z. (2009). Urban Three-Dimensional Expansion and its Driving Forces - A Case Study of Shanghai, China. Chinese Geographical Science, 19(4), 291-298. doi.org/10.1007/s11769009-0291-x

Mwangi, P. W., Karanja, F. N., \& Kamau, P. K. (2018). Analysis of the Relationship between Land Surface Temperature and Vegetation and Built-Up Indices in Upper-Hill, Nairobi. Journal of Geoscience and Environment Protection, 06(01), 1-16. doi.org/10.4236/gep.2018.61001

Nairobi City County. (2006). A Guide of Nairobi City Development Ordinances and Zones. Nairobi.

Peng, F., Gong, J., Wang, L., Wu, H., \& Yang, J. (2016). Impact of Building Heights on 3D Urban Density Estimation from Spaceborne Stereo Imagery. International Archives of the Photogrammetry, Remote Sensing and Spatial Information Sciences - ISPRS Archives, 41(July), 677-683. doi.org/10.5194/isprsarchives-XLI-B3-677-2016

Popovich, V., Schrenk, M., Thill, J.-C., Claramunt, C., \& Wang, T. (2018). A New Method to Characterize Density Adapted to a Coarse City Model. In Information Fusion and Intelligent Geographic Information Systems (IF \& IGIS'17) (p. 15). https://doi.org/10.1007/978-3-642-31833-7

Republic of Kenya. (2009). Building Code of the Republic of Kenya (2009 Edition) (Vol. 169). Nairobi.

Saha, K. (2014). DSM Extraction and Evaluation from Cartosat-1 Stereo Data for Bhopal city , Madhya Pradesh. International Journal of Scientific and Research Publications, 4(5), 4-8.

Schläpfer, M., Lee, J., \& Bettencourt, L. M. A. (2015). Urban Skylines: Building Heights and Shapes as Measures of City Size.
Retrieved from http://arxiv.org/abs/1512.00946

Singh, S. P. (2013). Virtual 3D City Modeling: Techiques and Applications, $X L$ (November), 27-29.

Sokido, D. L. (2016). Density in Relation to Patterns of Built-forms (Case Study: Addis Ababa, Ethiopia). International Journal of Architecture and Urban Development, 6(3), 5-18.

United Nations Environment Programme, United Nations Centre for Human Settlements, \& Republic of Kenya. (2009). City of Nairobi Environment Outlook. Nairobi. doi.org/10.1109/VSGAMES.2015.7295756

Upper Hill District Association. (2017). UHDA Newsletter. Nairobi.

Van de Voorde, T., Jacquet, W., \& Canters, F. (2011). Mapping Form and Function in Urban Areas: An Approach Based on Urban Metrics and Continuous Impervious Surface Data. Landscape and Urban Planning, 102(3), 143-155. doi.org/10.1016/j.landurbplan.2011.03.017

Wetangula, J., \& Mazurewicz, M. (2017). Market Research Preliminary Report: The Construction Market in Kenya. Nairobi. 